is mild and dry, with daily gentle exercise, avoiding over-exertion and fatigue, the best of which, by far, when attainable, is that derived from horse exercise. Sailing on the sea, when moderately agitated, if it do not excite too great nausea, is an admirable remedy in the early stage of the complaint; in fact, cruising round the coast at repeated short intervals, by avoiding the inevitable ennui, consequent on a protracted sea expedition, is preferable to a voyage to a more distant, though, as it too frequently proves, to the unfortunate patient, less happy land.

Travelling (provided the circumstances of the invalid admit of the comforts of home, combined with the strictest regard to the improvement of the general health), by varying the air and scene, and allowing habitual exposure to its invigorating influence, and thereby tranquillising the mind, proves in many cases a useful auxiliary.

In the winter months a leather waistcoat, worn over thin flannel during the day, may be prudently and advantageously recommended to those, who, either from natural or acquired susceptibility, are more or less prone to the disease.

Having completed the review of the several remedies which, under the author's personal observation, have proved from time to time, according to the peculiar features of the case, of decided benefit, he cannot conclude without strenuously urging the incalculable importance of investigating the earliest and most incipient threatenings of the disease. On this subject Sir James Clark graphically remarks, "It is too often far advanced when the patient is said to be threatened with it, and tracheal or bronchial irritation are the terms employed to account for symptoms which a closer investigation would trace to a deeper source. We must not be satisfied with a few slovenly thumps on the upper part of the chest, or even with the use of the ear or stethoscope for a few moments, applied as if we were afraid, rather than desirous of ascertaining the real condition of the lungs. Such superficial examination, if it deserve the name, is worse than useless; with the semblance of doing something, it really effects nothing, unless it be to deceive the patient and his friends, and bring this method of diagnosis into unmerited disrepute." "Nature will not be thus interrogated; her operations must be closely observed, and studied with attention, before we can hope rightly to interpret them."

\section{OVARIAN DROPSY.}

TO THE EDITORS OF THE PROVINCIAL MEDICAL JOURNAL.

Gentlemen,-If you think the accompanying case worthy of notice, I shall be much obliged by your inserting it in your valuable Journal.

I am, Gentlemen,

Yours, very truly, Robert Storrs.

Doncaster, Aug. 25, 1842.

The following case of ovarian dropsy occurred in my practice several years ago ; and, as it was somewhat peculiar, it may, perlaps, prove both interesting and instructive to the junior practitioner, who is apt to be too sanguine in the performance of an operation, or in the diagnosis of a case, and is too frequently unprepared for any unexpected or unforeseen occurrence which may perhaps arise, where he had been led to expect all as clear as he had been accustomed to read of in books, or in the graphic descriptions of a favorite lecturer. I had often heard the late Sir Astley Cooper describe an operation of this sort, where the operator coolly turned round on the assembled pupils, and pronounced it a case of dry tapping; but I little expected that the first case of the kind I should be called on to operate in would prove exactly similar.

In the year 1833 I was consulted by Sarah Firth, aged 42 , of Sprotborough, near this town, who had for some months been becoming gradually emaciated, with an enlarged and increasing abdomen, which had then become immensely distended, with very evident fluctuation, which was distinguishable even through her clothes; there was considerable anasarca of the legs; distressing sickness; costiveness and purging alternately; menstruation regular, though less than when in health; tongue red; countenance anxious ; pulse quick and weak. The swelling of the abdomen, she says, commenced on the right side, many months ago. The various sorts of treatment I adopted afforded no relief, except what she derived from severe purging, which somewhat abated the distension. She would not, however, consent to have the fluid evacuated until the distension was so great that the abdomen was quite tender to the touch, and she was occasionally delirious from the pain. My friend, Dr. Scholfield, who saw her with me, concurred in the propriety of the operation, and was with me on its performance, which took place November 5,1833 . On my withdrawing the trocar, to my surprise, not a drop of fluid passed through the canula, but at length, by pressure, and by repeatedly passing a probe through the canula, about a pint of gelatinous fluid was obtained; her weariness then became so great that we were obliged to desist. Nothing escaped from the puncture when the canula was withdrawn, and the puncture was merely covered with a strip of adhesive plaster. She continued much in the same state for some days, the distress from distention becoming more and more severe.

On the 12th I had just seen her, when I was again sent for in a hurry, and found that she had got relief from the opening made by the trocar, through which a large quantity of fluid had now come; it was partly gelatinous and partly serous, and escaped with great difficulty. I dilated the opening by means of a small piece of sponge, and obtained about a gallon more of semifluid. On the following day she felt so much relieved that she was anxious to have this repeated, which was donc. After this the fluid escaped by degrees. The sickness continued; the bowels could not be emptied by purgatives; the mucous membrane of the tonguc and mouth became aphthous; vomiting incessant; and she gradually sank, and died No. vember 20 th.

On the next day the body was opened by Dr. Scholfield and myself, and the following appearances were observed. A considerable quantity of semipurulent fluid in the cavity of the abdomen, the parietes of which were lined by loose lymph. On the right side was a large ovarian sac, containing a con- 
siderable quantity of gelatinous matter, and several set in a smoothly scooped wooden splint, without any small hydatids, and at the bottom of the sac was a bandaging whatever, the splint being only secured large tumor filling the greater part of the pelvis, and on a pillow, moulded into a form which embedded it ; containing a large quantity of fatty matter, some hair, water dressings were then applied, and assiduously and a quantity of shapeless bones. The uterus was persevered in for many days.

hard, and pushed forwards by the tumor; the bladder was capacious and natural; the rectum empty, and the colon distended with scybala from the tumor pressing on the rectum, and preventing the passage of solid faces; the other intestines were natural. The liver was paler than usual, but not much altered in texture ; the remaining viscera were healthy, except the stomach, which was considerably inflamed, and the left ureter was also considerably enlarged. Therc was a considerable quantity of bloody serum in the pericardium, otherwise all the viscera of the thorax were healthy. On a more minute inspection of the contents of the tumor at home, three teeth were

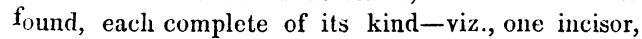
one bicuspid, and one molar tooth. The preparation I have now in my possession.

\section{CASE}

\section{OF}

\section{O M POU N D FRAC T UR E,} IN WHICH

REUNION WAS INTERRUPTED BY GESTATION.

By H. R. Oswald, Esq., Surgeon.

Several reasons induce me to consider the following case of compound fracture of the bones of the leg worth recording, and to place it at your disposal.

A compound fracture is at all times a dangerous injury, but this case is uncommonly interesting from considerable portions of the tibia having been removed at the first dressing, and from the fact that it occurred during the eighth month of pregnancy, and furnished a satisfactory proof that a fracture during pregnancy docs not reunite till after gestation has been com. pleted; and even after that period is past, remains long flexible, and deficient in hardness and strength.

On August 27, 1839, Mrs. R- aged twentyeight, and a native of the West Indies, in excellent health, received, whilst sitting in a gig, a kick from a vicions horse, which fractured both the bones of the right leg about their middle part. I visited this lady immediately after the accident, and found the foot and ankle doubled outwards, and a spicula of bone protruding through the thin integuments that cover the shin. This spicula was a loose portion of the lower end of the fractured tibia, and was surrounded with other loose and comminuted portions of the same end. The discharge of blood was inconsiderable, and swelling and reaction had only just commenced when I arrived; but owing to the importance of the case, and its occurring in a female large in the family way, I requested a consultation, and Mr. Garrett, of Douglas, was soon with me. We agreed to remove the loose and comminuted portions of bone, and consequently the wound of the integuments was immediately enlarged, and two fragments, consisting of the outer solid plate of the anterior surface of the tibia, one an inch, the other one inch and a half in length, besides other smaller portions, were removed. The limb was then extended to its proper position, and carefully

During the first week of the case, Mr. Edward Thompson and Mr. Stubbs, of Liverpool, who happened to be in the island, visited our patient, and were much pleased with the appearance of the wound, the position of the limb, and the general state of the case. Indeed, the very moderate degree of reaction, and the absence of constitutional as well as of local irritation and pain in the limb, were, from the first day, very remarkable, and I never saw a case so free of them. The consequences were, we had no difficulty in keeping the limb in position, and the case went on beautifully under the use of the water dressings and the usual attention to diet and regimen. Though I dreadcd the formation of abscesses where the broken ends of the bones had caused considerable injury to the soft parts of the calf of the leg, and in the large cavity out of which the comminuted portions of the tibia had been dissceted, yet none such took place. The wound digested kindly, and symptoms of the adhesive process, and of granulations filling up the cavity, were strikingly remarkable towards the close of the second week; and the tumefaction of the whole limb, which had been considerable, began to subside, and pit on pressure about the fourteenth day. It was, therefore, bandaged by the many-tailed bandage, and a portion of spirits added to the water dressings; a more generous diet was prescribed by allowing an addition of all egg or a slice of ham to breakfast, and a cutlct of meat or a basin of broth at dinner.

On the 23rd of September, being twenty-eight days after the accident, we removed the leg out of the splint for the first time, and found, as we suspected would be the case, the fracture quite flexible, as much so as it was on the first day. On examining the site where the callus ought to have been formed, we found the whole space soft and pulpy. The external wound, which had never given us any trouble, was now filled up and healed to the size of half an inch or less, and the swelling of the limb almost quite gone. The newly-formed cicatrix seemed to cover a large mass of granulations. There was no puriform discharge of any consequence, nor any sinus leading to deep-scated cavities; but no progress had been made to reunion by bone, and we were under the necessity of being as carcful in keeping the fracture in position as we were the first day it occurred. The many-tailed bandage was again applied, and, as labor was now daily expected, the limb was more firmly secured by splints all round. It may be remarked that, after the first week to the end of September, our patient suffered three exacerbations of fever of an aguish character, with intervals of eight days between each, but which produced no bad consequences beyond the uneasy sensations and loss of appetite for two or three days, which usually attend such attacks. On inquiry, I learned she had formerly suffered from ague, and considered that the present return of it was owing to the exhalations from the low meadow lands, and the streams of water which surrounded the cottage she occupied.

On the 28th of September labor set in very natu- 